\title{
XIX. On the utility of the oxygenated muriatic acid in the cure of scarlet fever; with an easy mode of preparing it for medical purposes
}

\section{Mr. John Ayrey Brathwaite}

To cite this article: Mr. John Ayrey Brathwaite (1804) XIX. On the utility of the oxygenated muriatic acid in the cure of scarlet fever; with an easy mode of preparing it for medical purposes, Philosophical Magazine Series 1, 18:70, 127-131, DOI: 10.1080/14786440408676459

To link to this article: http://dx.doi.org/10.1080/14786440408676459

曲 Published online: 18 May 2009.

Submit your article to this journal $\pi$

山 Article views: 2

View related articles 
tion, if to the left, must be subtracted, if to the right, added: thus $4^{\prime} 15^{\prime \prime}$ in the example just given being to the right, must be added.

Many more, and perhaps useful observations, might be given, and a mode of setting both glasses perpendicular to the plane of the instrument by the use of the above apparatus; but I fear I have already exceeded the limits allowed to communications in a monthly publication, and shall therefore add no more-except to say, it will give me much pleasure to find the present communication considered as useful.

February, 14, 1804 .

XIX. On the Utility of the Oxygenated Muriatic Acid in the Cure of Scarlet Fever; with an easy Mode of preparing it for Medical Purposes. By Mr. ЈоHN Ay REY Brathwatte, Member of the Royal College of Surgeons in London, and Surgeon to the Lancaster Dispensary*.

$\mathrm{H}$ $I_{\text {AVING frequently experienced the inefficacy of the com- }}$ mon mode of medical practice in the Scarlatina anginosa, I have been induced to make some inquiries into the nature, cause, and treatment of that disease, which has been prevalent in this town and neighbourhood for three years last past. The result of 'my observations has been the discovery of a remedy in this disease, which is as much entitled to infallibility, as mercury in the lues, or bark in the ague : it is easily prepared, by any apothecary, of materials with which his shop is, or ought to be, always supplied; and requires no complex pharmaceutical apparatus with which those unaccustomed to practical chemistry are often liable, even from proper materials, to prepare chemical preparations totally different in their properties from those intended.

As I have no doubt but the contaginn of the scarlet fever produces an extraordinary degree of disoxygenation of the system, with great debility, and exhaustion of the sensorial power; I was led to suppose that oxygen, exhibited in some easy and pleasant manner, might not only destroy the contagious matter adhering to the tonsils, uvula, \&c., but, by penetrating the fine moist membrane of the lungs, and by chemical attraction uniting with the blood, excite the action

* Communicated by the Author. 
of the arterial system, warming the extremities, increasing insensible perspiration, exhilarating the spirits, and, invigorating the vital principle without exhausting it, would prove an efficacious remedy in this but too tatal disease. This $I$ have experienced in the oxygenated muriatic acid, whose known property of destroying putrid miasms, and preventing infection, in a gaseous state, has totally aboished the absurd farragos of antient practice.

Variolous and vaccine virus, exposed but for a moment to the vapour of oxygenated muriatic acid, lose their contagious properties; and the latter, rubbed with one-eighth of a grain of oxide of iron (rubigo ferri), will rarely communicate the disease: what then may we not expect from this active and elegant preparation! elegant I may justly entitle it, as, when properly prepared and sufficiently diluted, it may be administered to patients of all ages, being a safe and efficacious remedy, possessed of a slight degree of grateful acidity.

When called to a patient, in whatcver stage of the scarlet fever, my practice for two years last past has uniformly been as follows :-One dram of oxygenated muriatic acid is mixed with eight ounces of distilled water in a vial, and shaken together: this quantity should be taken every twelve hours by a patient from fourteen to twenty years of age ; but it is preferable to administer it in draughts divided from the quantity above mentioned into $\xi_{i j}$, $\xi$ iss, $\bar{j}$, and $\xi$ ss bottles, as the patient's age and situation require, ordering them to be taken at such periods as for an adult to consume the quantity in the time mentioned, and to younger patients smaller doses, as halt a dram or two scruples of the acid to eight ounces of water. By this method the oxygen gas is not separated and lost each time the vial is opened, as may easily be perceived by its smell in the apartment. It is also absolutely necessary the medicine be placed in a dark situation, wrapped in paper, to prevent the disoxygenating influence of light.

Since the use of this medicine I have never had recourse to emetics, purgatives, blisters, or diaphoretics; a regular perseverance in the oxygenant remedy has universally succeeded, my patients rapidly recovering, and being seldom afflicted with those complaints succeeding the scarlet fever, such as pain of the joints, paucity of urme, and universal anasarcous swellings. Even should these follow, I recommend a continuance of the medicine until these symptoms entirely disappear, which will be found much earlier than by the usual inode of treatment. Indeed, if the axygenated 
preparation is duly persevered in, I am of opinion those painful and distressing affections will rarely occur. It is also possessed of this desirable property, that it may be easily taken by children, who generally are the most numerous patients in this disease, and to whom all medicines are administered with difficulty ; I have frequently heard them cry for that stuff which mended their throat, as they expressed it : indeed in that respect its effects are truly admirable, far surpassing the disagreeable practice of gargling and syringing, which in numerous instances, even if possible to do it, is productive of mischief. How far superior then must be a remedy which, by passing over the infected and frequently ulcerated part immediately, not only gives instantaneous relief, but entirely removes that fetid smell originating in severe cases from these parts! Patients often wish to be frequently sipping a little of the oxygenant liquid: which is not improper; but it must always be done out of a wine glass, as admeasurement with a spoon is dangerous, the oxygen rapidly oxidating the metal of which it is composed, and by that means conveying into the stomach a poisonous fluid, from which death might ensue.

The muriatic acid has long been used as a medicine, and sir William Fordyce strongly recommended it in the ulcerated sore throat and putrid fever; but the oxygenated muriatic acid has, I believe, been rarely employed. Dr. Crawford * once took twenty drops of it, diluted with water; but soon afterwards found an obtuse pain, with a sensation of constriction in the stomach and bowels : this uneasiness, notwithstanding the use of emetics and puryatives, lasted for several days, and was at last removed by drinking water impregnated with sulphureous hepatic air: this effect he attributes to the manganese, which had been used in the distillation of the acid, containing a portion of lead. I should rather suppose it proceeded from the dose of twenty drops being taken. Oxyggenated muriatic acid readily gives to living animal bodies its superoxygen, and the remains is common muriatic acid; a dose of which similar to the above would undoubtedly, in delicate constitutions, produce similar effects. In no case whatever have I found it necessary to exceed the quantity before mentioned, but it has sometimes been done by my patients through an anxious desire to get well: the same uneasiness has, however, been produced which Dr. Crawford experienced, though the preparation

* Philosophical Transactions, vol. $1 \times x x$. 


\section{Utility of Oxygenated Muriatic Acid in Scarlet Fever.}

was made so as not possibly to contain either lead or any other metallic substance.

To prepare the oxygenated muriatic acid in a perfect state of purity, put two ounces, by measure, of distilled water into a narrow tubulated bottle with a ground glass stopple; into this gradually pour, by measure also, as much muriatic arid, the specific gravity of which is as 1170 to 1000 of distilled water, frequently shaking the vial; add then to it two drams of oxymuriate of potash *, which in a little time will fall to the bottom, the acid seizing the small portion of alkali, and liberating beautiful globules of vital air, which slowly rise towards the surface, diminishing as they ascend, superoxygenating the acid: a little agitation now and then facilitates the process, but it will be three or four days before the acid becomes hyperoxygenated: the stopple should be put loosely into the vial and tied over with a piece of bladder, but not too tight, allowing it to move when the gas is rapidly extricated. This process should be, performed in a dark situation, and the oxygenant medicine be after preserved, by putting over the bottle a circular piece of pasteboard, to prevent it from being injured by the deoxygenating power of light.

It is not in scarlet fever only that this preparation promises to be of advantage; I have found it useful in angina maligna and other diseases proceeding from or producing a deoxygenation of the blood: in many lingering cases of the late influenza it was exhibited with evident advantage, in the doses above mentioned.

From the trials made by Guyton Morveau and others, it appears that the oxygenated muriatic acid in a gaseous form possesses the power of neutralizing and destroying contagious miasmata, even in rooms where the sick are present, without the slightest inconvenience. Possessed of amazing expansibility, this gaseous oxygenant diffuses itself over the most extensive apartments, feaving nothing untouched, and touching nothing it does not appropriate; rapidly oxidating metallic bodics, particularly iron and stecl, (which should be rewoved,) and radically destroying the nost offensive odours, thereby rendering innocuous perhaps deadly contagious poisons.

To completely purify any apartment, where a patient suffers in the scarlet fever or any other contagious disease, so

* The best oxymuriare of potash I ever had, was made by Mr. Hoyle, an ingenous chemist in Manchester; 100 grains yiclding nearly 74 cubic inches of oxygen gas. 
as to render it perfectly safe not only to the attendants but to the rest of the family, take a china teacup and saucer, put into the cup two ounces of common salt and half an ounce of the black oxide of manganese, previously powdered, with one ounce of water; then take an ounce and half of sulphuric acid, and pour a little of it now and then into the teacup among the other ingredients : immediately an amazing quantity of oxygenated muriatic acid gas will be disengaged, and diffused through the apartment: this should be suffered to remain only a few minutes, removing it out of the room into the staircase; by which means the whole house will become impregnated with this gaseous oxygenant : it will be proper to take it into the room frequently during the day, adding to it a little fresh sulphuric acid, and then replacing it in its former situation.

It was my intention to have transmitted a more minute account of the scarlet fever, and its mode of treatment by this oxygenant remedy, illustrated with cases; but suffering at present under an arthritic complaint, I found myself inadequate to the undertaking: perhaps at some future period I may again take up the pen to corroborate what I have asserted : should this, however, be the means of rescuing one individual from a premature grave, the intention of the writer will in some degree be accomplished.

Lancaster,

March I, ISo4.

XX. Report of Galvanic Experiments made on Men and Animals. Read to the Class of the Exact Sciences of the Academy of Turin by C. Rossi*.

I. Experiments on Rablits suffocated in Water. Thermometer $7^{\circ} \uparrow$; barometer 27 inches; pile 25 disks.

$\mathrm{H}$ the stomach of a the stomach of a rabbit, I suffocated it in a pail of water, and, as it gave no apparent signs of life, I galvanized it for twenty minutes : but in vain, as it was really dead. I did the same thing to another, which I drew sooner from the water, that is to say, while it still exhibited signs of life; but I was not able to save it by means of galvanism.

* From the Fournal de Pbysique, Vend. an. 12.

+ We suppose Reaumur's is meant $=44^{\circ} 6$ Fahr. -EDit . 